\title{
EFFECTS OF ATOMIC RADIATION
}

$\mathrm{F}^{\mathrm{o}}$ OUR years after its first report on the "Effects of Atomic Radiation"1, the United Nations Committee has issued a second one which integrates information received up to March 1962 *. This is not a revised version of the first report but an entirely new document, laid out along the lines of the first. About nine-tenths of the volume consist of 'annexes' dealing with the various physical and biological aspects of the subject. These and the numerous tables accompanying them embody an enormous amount of information from a great variety of sources and will be of great value to anybody interested in any particular aspect of radiation physics or biology. In the first part, the evidence from the annexes is summarized and evaluated in a number of 'chapters'. The presentation of the material is better arranged and less repetitive than in the first report, but it remains exceedingly difficult to collect all relevant information on any particular item. An index would overcome this difficulty.

The 'chapters' can be read with great profit by experts as well as by the broader public. I still feel that some of the annexes are overloaded with scientific details, more suitable for specialized reviews, but specialists may welcome these condensed reports of evidence from many widely scatterod sources. Of particular interest are the exhaustive literature lists, but readers must be warned that only items mentioned in the annexes can be located in these lists. Practically all reference numbers in the chapters are wrong, presumably because they were not altered when the original lists were increased by lastminuts additions.

Insufficient integration of late information is apparent also in tho sections dealing with the genetical effects of the atom bomb explosions in Japan. While the early evidence for such effects was at the best only weak, data in a recent publication ${ }^{2}$ show not only a significant shift in the sex ratio of the offspring depending on the sex of the exposed parent, but also an increased incidence of certain defects and of early deaths. A reference to this paper can be found in one of the paragraphs of the annex on hereditary effects, but the concluding paragraphs of the same annex and the relevant portions of the summarizing chapter take no account of it.

The estimate of background radiation from natural sources has been increased by about 30 per cent through inclusion of neutrons from cosmic rays. Among man-made sources, medical irradiation, in particular X-ray diagnosis, still plays the major part. On the basis of all information received, largely from countries with advanced medical facilities, the gonad dose due to this source is calculated as 30 per cent of radiation from natural sources, the bonemarrow dose (responsible for the leukæmia risk) as between 40 and 80 per cent. "British data show considerable variability within the country and indicate that, if the best techniques and equipmont were used throughout the country, substantial reduction of the genetically significant dose (i.e. the average gonad dose weighted by the expected number of children) would be achieved." The risk due to fall-out from tests up to December 1961, again measured as a percentage of natural radiation, is calculated as 11 per cent for hereditary damage, 15 per cent for leukæmia, and 23 per cent for bone tumours, while the corresponding risks from continued testing at an assumed yearly rate of $1 \mathrm{Mc}$. strontium-90 and $10^{28}$ atoms of carbon-14 are estimated as 23, 28 and 43 per cent.

* Report of the United Nations Scientific Committee on the Effects of Atomic Radiation. General Assembly. Official Records: Seventh Session, Supplement No. $16(A / 5216)$. Pp. iv + 442. (New York: United Nations: London: H.M.S.0., 1962.) 5 dollars; 358.6 d.; 50 Swiss franes.
An attempt at a more realistic appraisal of radiation risks from fall-out is made by the introduction of the concept of "dose commitment", namely, "the tota! dose contribution that is being, and will be, delivered by the material injected during past explosions". In calculations of dose commitment, account is taken of geographical and population factors affecting the risk from fall-out. Dose commitments from natural sources in m.rems per year are estimated as 125 for the gonads, 130 for the cells lining bone surfaces, and 122 for the bone marrow. Dose commitments for these three systems from the assumed practice of testing during 1954-61 are estimated as 111,244 and 154 m.rems. About half the dose commitment will be reached by the year 2,000 , the exception being the contribution of carbon-14 which, with a half-life of 5,760 years, will have completed less than 1 per cent of its action by that time. If future testing is continued at the rate specified here, dose commitments per year will be 29 m.rems to the gonads, $57 \mathrm{~m}$.rems to the cells lining bone surfaces, and $35 \mathrm{~m}$.rems to the bone-marrow. Included in the calculation of the dose commitment are the shortlived isotopes ${ }^{89} \mathrm{Sr},{ }^{140} \mathrm{Ba}{ }^{140}+\mathrm{I}, \mathrm{a}$, and ${ }^{131} \mathrm{I}$, with half-lives of 51,12 and 8 days. The dose commitment of strontium89 is less than 1 per cent of that of ${ }^{90} \mathrm{Sr}$, while that of ${ }^{140} \mathrm{Ba}{ }^{140}+\mathrm{La}$ is negligible. Iodine-131, in spite of its short half-life, is of major importance for children (see later). During periods of testing, inhaled short-lived isotopes of cerium, rubidium and zirconium may provide an additional lung exposure of 5 m.rems.

Several nuclear accidents are discussed. The $L D_{50}$ for humans exposed to short-term whole-body radiation is estimated to lie between 300 and 500 rads. In the Oak Ridge accident in 1958, five persons received doses near the lower limit of this range. All of them rocovered without visible damage. To this, however, must now be added the more recent eytological finding ${ }^{3}$ that in 1962 the blood of all these persons showed a high proportion of abnormal chromosome counts and of chromosome abnormalities. A smaller proportion of similar abnormalities was found in the blood of persons who, in the same accident, had been exposed to lower doses. After the Windscale accident, the ${ }^{131} \mathrm{I}$ content of milk in neighbouring farms was more than $1 \mu c . / 1$., a dose that is considered equivalent to 130 rads, that is, to more than half the dose $(200 \mathrm{r}$.) that, given as $\mathrm{X}$-rays to the necks of young children, produced cancer of the thyroid in about 3 per cent of them. Although this highly contaminated milk was withdrawn from the market, there remains the disturbing fact that the controls, that is, milk samples taken in this same area before the accident, contained $44 \mu \mu \mathrm{c}$. iotine-131/1. as compared with $5 \cdot 6$ in the United Kingdom as a whole.

The special danger of ${ }^{131} \mathrm{I}$ for children lies not only in their high intake of milk but also in the fact that, for the same milk consumption, the thyroid of children concentrates more iodine than that of adults. For a ten-week period and with a level of $125 \mu \mu \mathrm{c}$. iodine-131/1. milk the thyroid dose in m.rems is estimated as 170 for children of 6 months, 45 for children of 3 years, 25 for 10 -year-old children, and 4 for adults. Similarly, strontium isotopes accumulate to a higher degree in the bones of children than in those of adults. In a survey of ${ }^{\circ 0} \mathrm{Sr}$ in human bones, carried out in North America in 1960, the amount as measured in $\mu \mu \mathrm{c} . / \mathrm{g}$ calcium dropped from 2.3 in children less than 4 years, over 1.5 in children in the age range $5-10$, to $0 \cdot 3$ in individuals past the age of 19 . The figure for new-born infants was $1 \cdot 1$, showing that the foetus concentrates maternally received ${ }^{90} \mathrm{Sr}$ in its bones. 
In addition to accumulating disproportionate amounts of isotopes, the foetus may also be more sensitive to their damaging effects. This has been found to be true for exposure to external sources of radiation. Even low doses may induce developmental disorders or malignant changes in embryos. Doses of 3-5 rads given to pregnant women during the months $6-6 \frac{1}{2}$ of pregnancy led to a highly significant increase in the presence of aberrantcolour sectors in the iris of the new-born children. Although this abnormality is entirely harmless, its increase after such low doses indicates the unusually high sensitivity of embryonic tissue. At the time of this report, the question whether maternal irradiation during gestation may cause leukæmia of the child was still under debate. Meanwhile, a recent investigation by MacMahon ${ }^{4}$ supports Alice Stewart's findings. The increased risk to the child of developing leukæmia or other forms of cancer after irradiation in utero has boen estimated as 40 per cent. Whether there exists a threshold dose for the production of leukæmias and other malignancies in adults is still an unsolved question. Shortening of life-span has been proved for animals and is considered probable also for man.

The genetical risk is expressed in terms of the "genetically significant dose", that is, the average gonad dose weighted by the expected number of children. The newly recognized chromosomal abnormalities due to non-disjunction, occasionally to translocation, have been included among genetically caused abnormalities. It is estimated that about 1 per cent of all new-born earry some such chromosomal abnormality, while another I per cent suffer from some harmful trait with clear genetical basis (mainly a dominant autosomal gene). To this are added 4 per cent suffering from developmental malformations and serious constitutional disorders, including mental illness, the hereditary basic of which is not clearly understood. The overall estimate of 6 per cent born with some hereditary defect is a minimal figure for "it is generally accepted that there is a genetic component in much, if not all, illness". The possibility that some harmful traits may be maintained not through mutation pressure but through heterozygous advantage is considered as applying mainly to localized areas with special environmental conditions. The general frequency of such traits is considered to be exceedingly low. This is important because the frequency of this type of mutation is more or less independent of the amount of radiation received. The members of the Committee, as indeed all geneticists, consider it as "reasonably certain that the overwhelming majority of newly arising mutations have detrimental consequences and that, if beneficial mutations arise at all, the frequency of their occurrence is so low as to be unlikely to offset the burden occasioned by the harmful ones".

There is evidence from recent work on mice and, it should be added, from very old work on Drosophila that chromosomal abnormalities due to non-disjunetion are increased by $\mathrm{X}$-rays. For gene mutations, the linear doseeffect relationship has now been established down to doses of $8.5 \mathrm{r}$. in bacteria and $5 \mathrm{r}$. in Drosophila. The absence of a threshold for the genetical effects of radiation, which is strongly indicated by these findings, is in no way in- validated by the fact that the absolute amount of damage from a given dose of radiation varies with a number of factors: type of radiation, rate of delivery, type of genetical change scored, type of exposed tissue, degroe of oxygenation as well as various other environmental and physiological conditions. In mice, dose-rate (or intensity of delivery) influences mutation frequency in immature germ cells but not in spermatozoa, chronic radiation at $8.5 \times 10^{-3} \mathrm{r}$. $/ \mathrm{min}$ being less effective by a factor of about 4 than acute radiation at $90 \mathrm{r}$. $/ \mathrm{min}$. There is, however, no reason to suppose that lowering the dose-rate even more would result in a further decrease of mutation frequency; intensities of $8.5 \times 10^{-3} \mathrm{r}$. $/ \mathrm{min}$ and $1 \times 10^{-8}$ r./min had the same effect. Estimates of actual genetical risks are again expressed by the "doubling dose", that is, the dose that, if present as a permanent background, would double the present burden of hereditary defects. While the 1958 report suggests a doubling dose between 10 and 100 rads, with 30 as the most probable value, it is now estimated that, for acute radiation, the combined value for both sexes is somewhat lower than 30 rads but not less than 15, while for chronic radiation the most probable value is 100 rads or possibly more. Since results with Drosophila suggest a 2 per cent dominance of lethals and semi-lethals, most of the impact of a permanent doubling dose would be felt in about 50 generations. Some, or perhaps most, of this dominant damage may be expressed as an increased death-rate in early life; in experiments on mice, the offspring of irradiated parents had a higher mortality than control animals during the early part of life.

In its concluding remarks, the Committee states: "There should be no misunderstanding about the reality of genetic damage from radiation. Although individual mutations vary greatly in their effect, there is no doubt that any increase in mutation is harmful". "The exposure of mankind to radiation from increasing numbers of artificial sources, including the world-wide contamination of the environment with short- and long-lived radionuclides from weapons tests, calls for the closest attention, particularly because the effects of any increase in radia. tion exposure may not be fully manifested for several decades in the case of somatic disease, and for many generations in the case of genetic damage." "The Committee therefore emphasizes the need that all forms of unnecessary radiation exposure should be minimized or avoided entirely, particularly when the exposure of large populations is entailed; and that every procedure involving the peaceful uses of ionizing radiation should be subject to appropriate immediate and continuing scrutiny in order to ensure that the resulting exposure is kept to the minimum practical level." "As there are no effective measures to prevent the occurrence of harmful effects of global radioactive contamination from nuclear explosions, the achievement of a final cessation of nuclear tests would benefit present and future generations of mankind."

\section{Auerbach}

${ }^{1}$ Auerbach, C., Nature, 182, 1543 (1958).

= Bellefeuille, P. de, Acta Rad., 56, 65, 145 (1961).

- Bender, M. A., and Gooch, P. C., Rad. Res., 16, 44 (1962).

- MacMahon, B., J. Nat. Cancer Inst., 28, 1173 (1962).

\title{
THE INTERNATIONAL BRAIN RESEARCH ORGANIZATION
}

\author{
By Prof. H. WAELSCH \\ Columbia University, New York, N.Y.
}

$\mathrm{T}$ HE International Brain Research Organization (IBRO) was founded under the auspices of Unesco in response to the demand from scientists of different disciplines from many countries for the creation of an organization on a world-wide scale for the better mobiliza- tion and utilization of scientific resources of research on the brain. Although details of its short history may be found in the IBRO Bulletin (I, No. 1; 1962) it may be recalled here that the creation of the Organization stems directly from a resolution passed by the members of the 